\title{
Does the insurance status influence in-hospital outcome? A retrospective assessment in 30,175 surgical trauma patients in Switzerland
}

\author{
Lukas Funke $^{1} \cdot$ Claudio Canal $^{1} \cdot$ Franziska Ziegenhain $^{1} \cdot$ Hans-Christoph Pape ${ }^{1} \cdot$ Valentin Neuhaus $^{1}(\mathbb{0}$
}

Received: 21 November 2020 / Accepted: 28 April 2021 / Published online: 28 May 2021

(c) The Author(s) 2021

\begin{abstract}
Introduction There has been growing evidence in trauma literature that differences in insurance status lead to inequality in treatment and outcome. Most studies comparing uninsured to insured patients were done in the USA. We sought to gain further insights into differences in the outcomes of trauma patients in a healthcare system with mandatory public health coverage by comparing publicly versus privately insured patients.

Methods We used a prospective national quality assessment database from the Arbeitsgemeinschaft für Qualitätssicherung in der Chirurgie (AQC). More than 80 surgical departments in Switzerland are part of this quality program. We included all patients in the AQC database with any S- or T-code diagnosis according to the International Classification of Diseases ICD-10 (any injuries) who were treated during the 11-year period of 2004-2014. Missing insurance status information was an exclusion criterion. In total, 30,175 patients were included for analysis. The primary outcome was in-hospital mortality. Secondary outcomes included overall and intra- and postoperative complications. Bi- and multivariate analyses were performed, adjusted for insurance status, age, sex, American Society of Anesthesiologists (ASA) physical status category, type of injury, and surgeon's level of experience.

Results In total, $76.8 \%(n=23,196)$ of the patients were publicly insured. Patients with public insurance were significantly younger $(p<0.001)$, more often male $(p<0.001)$, and in better general health according to the ASA physical status category $(p<0.001)$. Length of pre- and postoperative stay and the number of operations per case were similar in the two groups. Patients with public insurance had a lower mortality rate $(1.3 \%$ vs. $1.9 \%, p<0.001)$, but after adjusting for confounders, insurance status was not a predictor of mortality. Overall complication rates were significantly higher for publicly insured patients $(8.4 \%$ vs. $6.2 \%, p<0.001)$, and after adjusting for confounders, insurance status was identified as an independent risk factor for overall complications $(p<0.001)$.

Conclusion Differences exist with respect to patient and procedural characteristics: publicly insured patients were younger, more often male, and scored better on ASA physical status. Insurance status seems not to be a predictor for fatal outcome after trauma, although it is associated with complications.
\end{abstract}

Keywords Insurance status · Orthopaedic trauma $\cdot$ Outcome

Valentin Neuhaus

Valentin.neuhaus@gmx.ch

Lukas Funke

lukas.funke@uzh.ch

Claudio Canal

claudio.canal@usz.ch

Franziska Ziegenhain

franziska.ziegenhain@usz.ch
Hans-Christoph Pape

Hans-Christoph.Pape@usz.ch

1 Division of Trauma Surgery, Department of Traumatology, University Hospital Zurich, University of Zurich, Raemistrasse 100, CH-8091 Zurich, Switzerland 


\section{Introduction}

There has been growing evidence in medicine that differences in insurance status lead to inequality regarding the outcome of various diseases. For example, uninsured and Medicaid populations were at greater risk of developing postoperative complications and dying, compared to privately insured patients, after surgery for colorectal carcinoma [1,2]. Similarly, patients with non-private insurance had higher morbidity and mortality rates after radical prostatectomy compared with privately insured patients [3]. In addition, being uninsured led to a poorer prognosis in oral cavity cancer attributed to an advanced stage of the disease or treatment in less specialised clinics [4]. All these studies were done in the United States and therefore focused on comparing uninsured with insured patients.

Do these differences in treatment and outcome also exist in trauma care? Trauma care often follows protocols [5] and has a rather standardized system of care. Thus, treatment is often initiated directly without the patient's insurance status being known, so there should be fewer insurance-biased treatment choices compared to other medical fields. Nevertheless, a growing body of trauma literature suggests a relationship between insurance status and the outcome of trauma. Nearly all studies have shown a higher mortality rate for uninsured patients [6-13].

In Switzerland, the Federal Health Insurance Act of 1996 made health insurance compulsory for everyone and introduced a standard benefits package [14]. Services not included in this package can be acquired through additional private insurance. Such services include, among others, free choice of hospital, hospital stays in single rooms, and exclusive treatment from senior physicians.

The question of whether these differences between public and private insurance impact the treatment and outcome of trauma patients has so far been studied very little in countries with compulsory health insurance. An initial study in a Swiss level-one trauma centre found some evidence of an association of insurance status with treatment and outcome of trauma patients [15]. The relationship between insurance status and treatment as well as outcome is likely very complex. To gain further insights, we examined a large cohort treated in 70 different surgical institutions in Switzerland to see whether the level of insurance is associated with variables like mortality, complications, and length of stay.

\section{Methods}

\section{Study design}

The data for this retrospective study were gathered using a prospective surgical registry from the "Working Group for Quality Assurance in Surgery" ("Arbeitsgemeinschaft für Qualitätssicherung in der Chirurgie," AQC). The AQC is an association of chief and attending physicians whose purpose is to collect data on various interventions and surgical diseases and injuries [16]. Through scientific analyses of the collected data, important insights are gained for quality assurance in surgery. Since 1995, the tool has been successfully used to ensure more transparency and a resulting increase in quality in Swiss surgery [17]. More than 80 Swiss surgical departments are part of the AQC ( $85 \%$ of all Swiss surgical departments). They register their surgical cases online using the AdjumedCollect tool [18].

The AQC database is based on a two-part questionnaire. The first part collects information concerning the operation(s), including type of operation (outpatient vs. inpatient and elective vs. emergent), number of operations (per hospitalisation), Swiss surgical procedure classification (CHOP) [19], level of surgeon's experience (resident, junior or senior consultant), duration of the procedure, need for transfusion(s), anaesthesia as well as intra- or postoperative complications (directly related to the procedure). Patient information is collected in the second part of the questionnaire, which includes age, sex, admission type (emergency, planned), level of insurance, diagnosis codes according to ICD-10 [20], the American Society of Anaesthesiologists (ASA) physical status category [21], thromboembolism prophylaxis or therapy, hospitalisation duration, ICU admission, general/overall complications (e.g., pneumonia), type of discharge (lethal outcome included)

The AQC registry contains only anonymised health data and therefore complies with the authorisation requirements of the local cantonal ethical review board (Zurich, Switzerland) without being subject to approval [22].

\section{Study subjects}

Included were 31,692 patients found in the AQC Register between 2004 and 2014 with an S or T diagnosis code according to the ICD-10 [20]. The ICD-10 is an international classification of diseases and related health problems. It is divided into 22 chapters (e.g., Chapter 9 is about diseases of the circulatory system). Chapter 19 (S- and T-codes) relates to injury, poisoning, and certain 
other consequences of external causes. S-codes are mainly based on anatomic areas (e.g., head, neck, chest). T-codes represent mainly multiple body injuries, burns, and certain early complications. Missing information about insurance status was an exclusion criterion and was applied to 1,517 patients. Ultimately, 30,175 patients were analysed.

\section{Variables and outcome measures}

The aim was to investigate outcome differences due to insurance status. Therefore, the level of insurance was stratified into public and private; the latter also included semiprivate.

Our primary outcome measurement was in-hospital mortality. Secondary outcome measurements included overall, intra- and postoperative complications, as well as length of stay.

Possible confounders, such as age, sex, ASA physical status, type of injury, experience level of surgeon, surgery and ICU duration, and thromboembolism and antibiotic prophylaxis were assessed. Due to missing data, we could not assess the type of procedure as a possible predictor/confounder for mortality and complications.

\section{Statistical analysis}

Analysis between groups of categorical data was done using the Chi square or Fisher exact test and presented as the number of patients and percentages. The unpaired $t$ test was used to compare two groups of continuous data, and results are presented as means \pm standard deviation.

Age, sex, ASA physical status, type of injury, experience level of surgeon, surgery and ICU durations, and thromboembolism and antibiotic prophylaxis were chosen as potential risk factors for mortality and complications. These risk factors were evaluated as confounders in a stepwise backward likelihood logistic regression analysis. A $p$ value of $<0.001$ was considered statistically significant; a $p$ value of 0.001-0.049 showed suggestive evidence. The SPSS Statistics program (version 25, IBM software, Armonk, NY) was used to analyse the data.

\section{Results}

\section{Demographic data}

This study included a total of 30,175 injured patients with a mean age of 54 years treated in 70 Swiss hospitals between 1 January 2004 and 31 December 2014; 50.2\% were male. The most common injuries included knee and lower leg (29.6\%), elbow and forearm (17.0\%), and hip and thigh injuries (16.9\%).

\section{Association of insurance status and patient/ procedural characteristics}

In total, $76.8 \%(n=23,196)$ of the patients were publicly insured. Patients with public insurance were significantly younger ( 53 vs. 61 years), more often male $(52.7 \%$ vs. $41.8 \%$ ), and healthier (according to ASA physical status category) than privately insured patients $(p<0.001)$ (Table 1$)$.

Patients with public insurance were operated by less experienced surgeons $(p<0.001)$ and had longer procedural durations $(p<0.001)$. They also stayed longer in the intensive care unit $(p=0.049)$ and were intubated more often $(p=0.038)$. In addition, the public cohort received lower thromboembolism prophylaxis $(p<0.001)$ and prophylactic antibiotics $(p<0.001)$ (Table 2).

\section{Outcome}

Pre- and postoperative length of stay, number of operations per case, and postoperative complications were similar for both groups.

Publicly insured patients had a lower mortality rate (1.3\% vs. $1.9 \% ; p<0.001)$. Public insurance status was not revealed as a risk factor for mortality in multivariate analysis.

Publicly insured patients had a higher chance of intraoperative complications ( $0.6 \%$ vs. $0.4 \% ; p=0.045)$. The most common intraoperative complications were: (1) other complications, (2) fracture, (3) artery lesion, (4) nerve lesion, and (5) tendon lesion. In addition, overall complications were seen more often in the public cohort (8.4\% vs. 6.2\%; $p<0.001)$. In multivariate analysis for any complication, public insurance status remained an independent risk factor for complications (OR 1.78, 95\% CI 1.49-2.14, $p<0.001$ ). The public cohort was discharged to a rehabilitation clinic less often $(6.9 \%$ vs. $11.4 \% ; p<0.001)$ (Tables $3,4,5)$.

\section{Discussion}

In the United States, disparities have been reported in treatment and outcome of trauma patients due to unequal insurance status. In Switzerland, basic healthcare is universal, but patients may optionally pay for private insurance. One Swiss study showed less favourable outcomes in publicly insured patients [15].

In this study, we focused on in-hospital mortality and complications. After analysing 30,175 orthopaedic trauma patients, we found publicly insured patients to be younger, more often male, and in better general health according to their ASA physical status. Public insurance was independently associated with complications but not with mortality. Significant predictors for mortality or complications were higher age, male sex, higher (worse) ASA physical status 
Table 1 Public vs. Private, Patient Characteristics

\begin{tabular}{|c|c|c|c|c|c|}
\hline \multirow[t]{2}{*}{ Parameter } & \multicolumn{2}{|c|}{$\begin{array}{l}\text { Public } \\
(n=23,196)\end{array}$} & \multicolumn{2}{|c|}{$\begin{array}{l}\text { Private } \\
(n=6979)\end{array}$} & \multirow[t]{2}{*}{$p$ value } \\
\hline & $n$ & $\%$ & $n$ & $\%$ & \\
\hline \multicolumn{6}{|l|}{ Age (years) } \\
\hline Mean \pm SD & \multicolumn{2}{|l|}{$53 \pm 24$} & \multicolumn{2}{|l|}{$61 \pm 20$} & $<0.001$ \\
\hline \multicolumn{6}{|l|}{ Sex } \\
\hline Male & 12,235 & 52.7 & 2919 & 41.8 & \multirow[t]{2}{*}{$<0.001$} \\
\hline Female & 10,961 & 47.3 & 4060 & 58.2 & \\
\hline \multicolumn{6}{|l|}{ ASA } \\
\hline I (healthy) & 9667 & 43.2 & 2105 & 33.5 & \multirow[t]{5}{*}{$<0.001$} \\
\hline II (mild systemic disease) & 8827 & 39.5 & 2970 & 47.3 & \\
\hline III (severe systemic disease) & 3614 & 16.2 & 1140 & 18.2 & \\
\hline IV (severe systemic disease with constant threat to life) & 249 & 1.1 & 62 & 1.0 & \\
\hline $\begin{array}{l}\mathrm{V} \text { (moribund person who is not expected to survive } \\
\text { without the operation) }\end{array}$ & 9 & 0.0 & 2 & 0.0 & \\
\hline \multicolumn{6}{|l|}{ Admission type } \\
\hline Emergency & 16,006 & 69.0 & 4679 & 69.8 & \multirow[t]{3}{*}{ n.s } \\
\hline Registered, planned & 7115 & 30.7 & 2010 & 30.0 & \\
\hline Other & 72 & 0.3 & 15 & 0.2 & \\
\hline \multicolumn{6}{|l|}{ Diagnosis (ICD-10) } \\
\hline S00-S09: Head Injury & 227 & 1.0 & 87 & 1.2 & \multirow[t]{11}{*}{$<0.001$} \\
\hline S10-S19: Neck Injury & 21 & 0.1 & 7 & 0.1 & \\
\hline S20-S29: Thoracic Injury & 239 & 1.0 & 89 & 1.3 & \\
\hline S30-S39: Abdominal, lumbosacral, LWS, pelvis injury & 359 & 1.5 & 115 & 1.6 & \\
\hline S40-S49: Shoulder and upper arm injury & 2831 & 12.1 & 885 & 12.7 & \\
\hline S50-S59: Elbow and forearm injury & 3935 & 16.9 & 1188 & 17.0 & \\
\hline S60-S69: Wrist and hand injury & 1429 & 6.1 & 154 & 2.2 & \\
\hline S70-S79: Hip and thigh injury & 3835 & 16.4 & 1265 & 18.1 & \\
\hline S80-S89: Knee and lower leg injury & 6783 & 29.1 & 2160 & 30.9 & \\
\hline S90-S99: Ankle and foot injury & 783 & 3.4 & 161 & 2.3 & \\
\hline T00-T98: Any T code & 2883 & 12.4 & 870 & 12.5 & \\
\hline
\end{tabular}

SD Standard Deviation, ASA American Society of Anesthesiologists Classification system, n.s. not significant, ICD International Classification of Diseases classification, and certain injuries (head, hip, and thigh for mortality; chest, hip, and thigh for complications). We found insurance status to have no effect on length of stay and number of operations per hospitalization.

Our study has several strengths and limitations. One of its strengths is the large sample size with data from multiple institutions. Another strength is the AQC database whose input is voluntary and prospective. This means there are no incentives for data input. The limitations in this study are the following: first, data from the AQC database only account for in-hospital outcomes. Long-term information could not be assessed. Second, our analysis relies on the accurate documentation that physicians entered and therefore lacks validation. Third, the database and ICD-10 classifications give us no information about trauma mechanisms and total injury severity, thereby preventing better risk adjustment analysis. Fourth, the AQC database has missing data in certain areas, especially in procedure codes. For that reason, we could not add this important covariate.

In this study, we found publicly insured patients to be more often male and younger as well as being in better general health (according to ASA physical status categories). These findings are unsurprising and in line with a singlecentre study from Switzerland by Jentzsch et al. [15] about the effects of insurance status on trauma patients. They are also congruent with overall fracture age and gender distribution curves published by Court-Brown and Caesar [23].

Patients with private insurance died significantly more often with a rate of $1.9 \%$ compared to publicly insured patients with a rate of $1.3 \%$. These findings suggest a relationship between private insurance and mortality, but after adjusting for confounders, neither private nor public insurance could be identified as a significant independent risk factor for mortality. These findings may reasonably be due 
Table 2 Public vs. Private, Procedure Characteristics

\begin{tabular}{|c|c|c|c|c|c|}
\hline \multirow[t]{2}{*}{ Parameter } & \multicolumn{2}{|l|}{ Public } & \multicolumn{2}{|l|}{ Private } & \multirow[t]{2}{*}{$p$ value } \\
\hline & $n$ & $\%$ & $n$ & $\%$ & \\
\hline \multicolumn{6}{|l|}{ Surgeon class } \\
\hline Senior consultant, attending surgeon & 9431 & 40.8 & 4651 & 71.7 & \multirow[t]{3}{*}{$<0.001$} \\
\hline Junior consultant & 8874 & 38.4 & 1384 & 21.3 & \\
\hline Resident & 4824 & 20.9 & 450 & 6.9 & \\
\hline \multicolumn{6}{|l|}{ Duration surgery (minutes) } \\
\hline Mean \pm SD & \multicolumn{2}{|l|}{$94 \pm 128$} & \multicolumn{2}{|l|}{$82 \pm 93$} & $<0.001$ \\
\hline \multicolumn{6}{|l|}{ Duration ICU (hours) } \\
\hline Mean \pm SD & \multicolumn{2}{|l|}{$3 \pm 33$} & \multicolumn{2}{|l|}{$2 \pm 23$} & 0.049 \\
\hline \multicolumn{6}{|l|}{ Need for intubation } \\
\hline No & 883 & 3.8 & 227 & 3.3 & 0.038 \\
\hline \multicolumn{6}{|l|}{ Thromboembolism prophylaxis } \\
\hline No & 3673 & 15.9 & 545 & 8.1 & \multirow[t]{3}{*}{$<0.001$} \\
\hline Yes & 18,111 & 78.2 & 5717 & 84.7 & \\
\hline Anticoagulation & 1374 & 5.9 & 488 & 7.2 & \\
\hline \multicolumn{6}{|l|}{ Antibiotics } \\
\hline No & 4894 & 21.2 & 1092 & 16.8 & \multirow[t]{4}{*}{$<0.001$} \\
\hline Prophylactic before incision & 15,426 & 66.8 & 4771 & 73.3 & \\
\hline Prophylactic after incision & 765 & 3.3 & 179 & 2.7 & \\
\hline Antibiotic therapy & 2024 & 8.8 & 471 & 7.2 & \\
\hline
\end{tabular}

$S D$ Standard Deviation, ICU Intensive Care Unit
Table 3 Public vs. Private, Outcome

\begin{tabular}{|c|c|c|c|c|c|}
\hline \multirow[t]{2}{*}{ Parameter } & \multicolumn{2}{|l|}{ Public } & \multicolumn{2}{|c|}{ Private } & \multirow[t]{2}{*}{$p$ value } \\
\hline & $n$ & $\%$ & $n$ & $\%$ & \\
\hline Intraoperative complications & 137 & 0.6 & 27 & 0.4 & 0.045 \\
\hline Postoperative complications & 751 & 3.2 & 218 & 3.1 & n.s \\
\hline Overall complications & 984 & 8.4 & 234 & 6.2 & $<0.001$ \\
\hline Mortality & 305 & 1.3 & 135 & 1.9 & $<0.001$ \\
\hline \multicolumn{6}{|l|}{ Discharge } \\
\hline Deceased & 305 & 1.3 & 135 & 1.9 & \multirow[t]{11}{*}{$<0.00$} \\
\hline At home & 18,554 & 80.2 & 5159 & 77.7 & \\
\hline Nursing home & 1008 & 4.4 & 219 & 3.3 & \\
\hline Old people's home & 751 & 3.2 & 186 & 2.8 & \\
\hline Psychiatry & 92 & 0.4 & 11 & 0.2 & \\
\hline Rehabilitation clinic & 1603 & 6.9 & 755 & 11.4 & \\
\hline Other hospital & 390 & 1.7 & 89 & 1.3 & \\
\hline Prison & 12 & 0.1 & 3 & 0.0 & \\
\hline Others & 205 & 0.9 & 48 & 0.7 & \\
\hline Unknown & 160 & 0.7 & 21 & 0.3 & \\
\hline Transfer to other ward & 57 & 0.2 & 15 & 0.2 & \\
\hline \multicolumn{6}{|l|}{ LOS preoperative (days) } \\
\hline Mean \pm SD & \multicolumn{2}{|l|}{$2 \pm 10$} & \multicolumn{2}{|l|}{$2 \pm 26$} & n.s \\
\hline \multicolumn{6}{|l|}{ LOS postoperative (days) } \\
\hline Mean \pm SD & \multicolumn{2}{|l|}{$7 \pm 12$} & \multicolumn{2}{|l|}{$8 \pm 27$} & n.s \\
\hline \multicolumn{6}{|l|}{ Number of operations per case } \\
\hline Mean \pm SD & $1 \pm 1$ & & $1 \pm 1$ & & n.s \\
\hline
\end{tabular}

n.s.:not significant, LOS Lenght of Stay, SD Standard Deviation to the fact that privately insured patients were older (61 vs. 53 years) and in worse general health according to their ASA physical status category. This hypothesis is underscored by several investigations showing that pre-existing health impairments have a significant negative influence on trauma patient outcomes, regardless of injury severity [24, 25]. Additionally, severe injuries involving the head, chest, hip, and thigh were more common in the private cohort of our study.

Literature comparing insured versus uninsured trauma patients has reported that predominantly uninsured patients had higher mortality rates [6-13]. Only one study by Taghavi et al. [26] disagreed and reported that they did not find a correlation between insurance status and mortality. Reasons for higher mortality, such as fewer resources directed to uninsured patients, are critically discussed rather than empirically confirmed [6,27]. Another possible reason is that insurance status may serve as a surrogate for other factors, such as socioeconomic status (SES). Lower SES has been linked to worse outcomes after non-fatal injury [28], and an association between SES and mortality has been discussed. Yet, a recent study denied a significant association between SES and mortality [29]. These contradictory findings and our results regarding mortality support the thesis that trauma care is often initiated without knowing the patient's insurance status and therefore leads to comparable treatment and outcomes. 
Table 4 Predictors for Mortality

\begin{tabular}{|c|c|c|c|c|}
\hline \multirow[t]{2}{*}{ Parameter } & \multirow[t]{2}{*}{ Sig } & \multirow[t]{2}{*}{ OR } & \multicolumn{2}{|l|}{$95 \% \mathrm{CI}$} \\
\hline & & & Lower & Upper \\
\hline ASA V (vs. ASA I) & $<0.001$ & 20.943 & 4.406 & 99.554 \\
\hline ASA IV (vs. ASA I) & $<0.001$ & 12.412 & 6.036 & 25.520 \\
\hline Head injury (vs. any $\mathrm{T}$ code) & $<0.001$ & 4.605 & 2.021 & 10.496 \\
\hline ASA III (vs. ASA I) & 0.005 & 2.582 & 1.336 & 4.989 \\
\hline Intubation yes & $<0.001$ & 2.206 & 1.454 & 3.345 \\
\hline Sex (male) & $<0.001$ & 2.072 & 1.562 & 2.747 \\
\hline Hip and thigh injury (vs. any $\mathrm{T}$ code) & 0.010 & 1.770 & 1.146 & 2.735 \\
\hline Abdominal, lumbosacral, LWS, pelvis injury (vs. any T code) & n.s & 1.461 & 0.633 & 3.372 \\
\hline Public insurance (vs. private) & n.s & 1.416 & 0.991 & 2.023 \\
\hline Junior consultant (vs. senior consultant) & n.s & 1.273 & 0.931 & 1.740 \\
\hline Antibiotic prophylaxis before incision (vs. no antibiotics) & n.s & 1.249 & 0.734 & 2.124 \\
\hline Antibiotics as therapy (vs. no antibiotics) & n.s & 1.166 & 0.626 & 2.175 \\
\hline Number of operations per case & 0.028 & 1.139 & 1.014 & 1.279 \\
\hline Thoracic injury (vs. any T code) & n.s & 1.077 & 0.384 & 3.019 \\
\hline Age & $<0.001$ & 1.060 & 1.046 & 1.074 \\
\hline Resident (vs. senior consultant) & n.s & 1.009 & 0.677 & 1.503 \\
\hline LOS preoperative & n.s & 1.006 & 0.980 & 1.034 \\
\hline ICU duration & $<0.001$ & 1.004 & 1.003 & 1.006 \\
\hline Duration surgery & 0.024 & 0.998 & 0.997 & 1.000 \\
\hline Wrist and hand injury (vs. any $\mathrm{T}$ code) & n.s & 0.983 & 0.288 & 3.357 \\
\hline ASA II (vs. ASA I) & n.s & 0.750 & 0.377 & 1.492 \\
\hline Thromboembolism prophylaxis (vs. no thromboembolism prophylaxis) & n.s & 0.645 & 0.368 & 1.130 \\
\hline Anticoagulation (vs. no thromboembolism prophylaxis) & 0.040 & 0.489 & 0.247 & 0.968 \\
\hline Ankle and foot injury (vs. any T code) & n.s & 0.420 & 0.056 & 3.131 \\
\hline Elbow and forearm injury (vs. any $\mathrm{T}$ code) & 0.003 & 0.235 & 0.089 & 0.619 \\
\hline Antibiotic prophylaxis after incision (vs. no antibiotics) & 0.042 & 0.206 & 0.045 & 0.945 \\
\hline Shoulder and upper arm injury (vs. any T code) & 0.002 & 0.104 & 0.024 & 0.441 \\
\hline Knee and lower leg injury (vs. any $\mathrm{T}$ code) & 0.001 & 0.037 & 0.005 & 0.272 \\
\hline
\end{tabular}

ASA American Society of Anesthesiologists classification system, n.s. not significant, LOS Length Of Stay, ICU Intensive Care Unit

The main predictors for complications were pre-existing medical conditions, need for anticoagulation, distinct injuries (such as chest and head injuries), and public insurance. Patients with public insurance more often had intraoperative and overall complications. The reasons are not yet clear. Longer duration of surgery was a comprehensible independent risk factor for complications. This could be due to the fact that publicly insured patients were more often operated by less experienced surgeons, but after adjusting for confounders, less experienced surgeons were not a predictor for complications. Another possible explanation could be that publicly insured patients were mainly attended by residents in contrast to residents and consultants in the case of privately insured patients. Also, other insurance-associated variables like hospital wealth, qualifications of the attending staff, nursing ratio, and pre-injury nutrition could have an effect on complications that develop throughout the hospital stay. However, this information is not provided in the database and cannot be verified.

Another reason for higher complication rates in publicly insured patients may be the injury severity. In our study, we could not assess for injury severity, so this remains just another potential explanation. Other literature comparing insured versus uninsured patients found injury severity not to differ between the two groups [7, 9, 26]; a study by Salim et al. [10] even indicates that uninsured patients had less severe injuries.

The higher complication rate in publicly insured patients is in contrast to Jentzsch et al. [15] who found no difference in complications between publicly and privately insured Swiss patients. This contrast may be due to their smaller sample size $(6000$ vs. 30,000$)$ or to a different patient population, as their study included only data from a level-one trauma centre. Another Swiss study on colorectal surgery also found no difference in complications between patients 
Table 5 Predictors for Complications

\begin{tabular}{|c|c|c|c|c|}
\hline \multirow[t]{2}{*}{ Parameter } & \multirow[t]{2}{*}{ Sig } & \multirow[t]{2}{*}{ OR } & \multicolumn{2}{|l|}{$95 \% \mathrm{CI}$} \\
\hline & & & Lower & Upper \\
\hline ASA IV (vs. ASA I) & $<0.001$ & 5.676 & 3.712 & 8.680 \\
\hline Anticoagulation (vs. no thromboembolism prophylaxis) & $<0.001$ & 2.433 & 1.571 & 3.770 \\
\hline ASA III (vs. ASA I) & $<0.001$ & 2.415 & 1.874 & 3.113 \\
\hline Antibiotics as therapy (vs. no antibiotics) & $<0.001$ & 2.096 & 1.533 & 2.866 \\
\hline Public insurance (vs. private) & $<0.001$ & 1.781 & 1.486 & 2.135 \\
\hline Antibiotic prophylaxis after incision (vs. no antibiotics) & 0.046 & 1.773 & 1.009 & 3.115 \\
\hline Thoracic injury (vs. any $\mathrm{T}$ code) & 0.016 & 1.687 & 1.103 & 2.578 \\
\hline Head injury (vs. any T code) & n.s & 1.645 & 0.989 & 2.735 \\
\hline Thromboembolism prophylaxis (vs. no thromboembolism prophylaxis) & 0.048 & 1.483 & 1.003 & 2.192 \\
\hline ASA V (vs. ASA I) & n.s & 1.428 & 0.161 & 12.640 \\
\hline Antibiotic prophylaxis before incision (vs. no antibiotics) & 0.014 & 1.417 & 1.074 & 1.870 \\
\hline Hip and thigh injury (vs. any $\mathrm{T}$ code) & 0.002 & 1.387 & 1.124 & 1.710 \\
\hline Sex (male) & $<0.001$ & 1.349 & 1.164 & 1.563 \\
\hline Number of operations per case & $<0.001$ & 1.258 & 1.200 & 1.318 \\
\hline ASA II (vs. ASA I) & n.s & 1.236 & 0.984 & 1.553 \\
\hline Intubation yes & n.s & 1.154 & 0.860 & 1.549 \\
\hline Abdominal, lumbosacral, LWS, pelvis injury (vs. any T code) & n.s & 1.089 & 0.743 & 1.598 \\
\hline LOS preoperative & $<0.001$ & 1.047 & 1.028 & 1.067 \\
\hline Age & $<0.001$ & 1.022 & 1.018 & 1.027 \\
\hline ICU duration & $<0.001$ & 1.005 & 1.003 & 1.006 \\
\hline Duration surgery & $<0.001$ & 1.002 & 1.002 & 1.003 \\
\hline Junior consultant (vs. senior consultant) & n.s & 0.972 & 0.826 & 1.144 \\
\hline Resident (vs. senior consultant) & n.s & 0.849 & 0.692 & 1.042 \\
\hline Shoulder and upper arm injury (vs. any $\mathrm{T}$ code) & $<0.001$ & 0.559 & 0.420 & 0.742 \\
\hline Knee and lower leg injury (vs. any T code) & $<0.001$ & 0.463 & 0.359 & 0.595 \\
\hline Elbow and forearm injury (vs. any T code) & $<0.001$ & 0.348 & 0.254 & 0.478 \\
\hline Ankle and foot injury (vs. any T code) & $<0.001$ & 0.291 & 0.152 & 0.556 \\
\hline Wrist and hand injury (vs. any $\mathrm{T}$ code) & $<0.001$ & 0.078 & 0.019 & 0.320 \\
\hline
\end{tabular}

ASA American Society of Anesthesiologists classification system, n.s. not significant, LOS Length Of Stay, ICU Intensive Care Unit

with state versus private healthcare insurance; however, the use of minimally invasive techniques was different in publicly and privately insured patients [30]. We must be aware that this data do not allow to control for a possible effect of over-treatment in patients with private insurance and to reassess the indications - at least the number of operations and length of stay were not significantly different in both insurance groups.

\section{Conclusion}

Differences exist with respect to patient and procedural characteristics in publicly versus privately insured patients. Public insurance is associated with younger age, male sex, and better ASA physical status scores. Insurance status does not seem to be a predictor of fatal outcomes after trauma; however, publicly insured patients are more often subject to complications.
These findings need to be interpreted in another country with a mandatory health insurance system.

Funding Open Access funding provided by Universität Zürich. The authors have no funding to declare.

\section{Declarations}

Conflict of interest The authors declare that they have no competing interests.

Ethical approval The data of this study bases on anonymized, de-identified data; our institutional review board waves the necessity from institutional review board approval.

Open Access This article is licensed under a Creative Commons Attribution 4.0 International License, which permits use, sharing, adaptation, distribution and reproduction in any medium or format, as long as you give appropriate credit to the original author(s) and the source, provide a link to the Creative Commons licence, and indicate if changes 
were made. The images or other third party material in this article are included in the article's Creative Commons licence, unless indicated otherwise in a credit line to the material. If material is not included in the article's Creative Commons licence and your intended use is not permitted by statutory regulation or exceeds the permitted use, you will need to obtain permission directly from the copyright holder. To view a copy of this licence, visit http://creativecommons.org/licenses/by/4.0/.

\section{References}

1. Kelz RR, Gimotty PA, Polsky D, Norman S, Fraker D, DeMichele A. Morbidity and mortality of colorectal carcinoma surgery differs by insurance status. Cancer. 2004;101(10):2187-94.

2. Roetzheim RG, Pal N, Gonzalez EC, Ferrante JM, Van Durme DJ, Krischer JP. Effects of health insurance and race on colorectal cancer treatments and outcomes. Am J Public Health. 2000;90(11):1746-54.

3. Trinh QD, Schmitges J, Sun M, Sammon J, Shariat SF, Zorn K, et al. Morbidity and mortality of radical prostatectomy differs by insurance status. Cancer. 2012;118(7):1803-10.

4. Shin JY, Yoon JK, Shin AK, Diaz AZ. The influence of insurance status on treatment and outcomes in oral cavity cancer: an analysis on 46,373 patients. Int J Oral Maxillofac Surg. 2018;47(10):1250-7.

5. 10 th Edition of the Advanced Trauma Life Support ® (ATLS (B) Student course manual. Chicago (IL): American College of Surgeons; 2018.

6. Haas JS, Goldman L. Acutely injured patients with trauma in Massachusetts: differences in care and mortality, by insurance status. Am J Public Health. 1994;84(10):1605-8.

7. Haider AH, Chang DC, Efron DT, Haut ER, Crandall M, Cornwell EE. Race and insurance status as risk factors for trauma mortality. Arch Surg. 2008;143(10):945-9.

8. Haider AH, Weygandt PL, Bentley JM, Monn MF, Rehman KA, Zarzaur BL, et al. Disparities in trauma care and outcomes in the USA: a systematic review and meta-analysis. J Trauma Acute Care Surg. 2013;74(5):1195-205.

9. Greene WR, Oyetunji TA, Bowers U, Haider AH, Mellman TA, Cornwell EE, et al. Insurance status is a potent predictor of outcomes in both blunt and penetrating trauma. Am J Surg. 2010;199(4):554-7.

10. Salim A, Ottochian M, DuBose J, Inaba K, Teixeira P, Chan LS, et al. Does insurance status matter at a public, level I trauma center? J Trauma. 2010;68(1):211-6.

11. Maybury RS, Bolorunduro OB, Villegas C, Haut ER, Stevens K, Cornwell EE, et al. Pedestrians struck by motor vehicles further worsen race- and insurance-based disparities in trauma outcomes: the case for inner-city pedestrian injury prevention programs. Surgery. 2010;148(2):202-8.

12. Rosen H, Saleh F, Lipsitz S, Rogers SO, Gawande AA. Downwardly mobile: the accidental cost of being uninsured. Arch Surg. 2009;144(11):1006-11.

13. Chikani V, Brophy M, Vossbrink A, Hussaini K, Salvino C, Skubic J, et al. Association of insurance status with health outcomes following traumatic injury: statewide multicenter analysis. West J Emerg Med. 2015;16(3):408-13.
14. Thomson S, Busse R, Crivelli L, van de Ven W, Van de Voorde C. Statutory health insurance competition in Europe: a four-country comparison. Health Policy. 2013;109(3):209-25.

15. Jentzsch T, Neuhaus V, Seifert B, Osterhoff G, Simmen HP, Werner CM, et al. The impact of public versus private insurance on trauma patients. J Surg Res. 2016;200(1):236-41.

16. AQC, Arbeitsgemeinschaft für Qualitätssicherung in der Chirurgie. Geschäftsstelle c/o adjumed services AG, Birmensdorferstrasse 470, 8055 Zürich. Available from http://www.aqc.ch/Willk ommen-bei-der-AQC/Willkommen-bei-der-AQC.aspx. (Accessed 14 Sept 2019).

17. Schöb O, Kocher T, Langer I. Die Selbststeuerung erhalten - fünf fragen an die medizinische qualitätssicherung. Bull Med Suisses. 2014;95(39):1446-8.

18. Adjumed Services AG, Birmensdorferstrasse 470, 8055 Zürich. https://www.adjumed.net/Default.aspx?ReturnUrl=\%2fWeb $\%$ 2fFaelle_Responsive.aspx.(Accessed 21 Nov 2019).

19. Schweizerische Operationsklassifikation (CHOP). https://www. bfs.admin.ch/bfs/de/home/statistiken/kataloge-datenbanken/publi kationen.assetdetail.9286150.html. (Accessed 25 Nov 2019).

20. International statistical classification of diseases and related health problems, 10th revision (ICD-10). https://www.who.int/classifica tions/icd/icdonlineversions/en/. (Accessed 25 Nov 19).

21. ASA physical status classification system. https://www.asahq.org/ standards-and-guidelines/asa-physical-status-classification-system. (Accessed 25 Nov 19).

22. Authorisation requirements. Kantonale ethikkommission zürich, stampfenbachstrasse 121, 8090 Zürich. https://kek.zh.ch/internet/ gesundheitsdirektion/kek/de/vorgehen_gesuchseinreichung/bewil ligunspflicht.html. (Accessed 03 Dec 2019).

23. Court-Brown CM, Caesar B. Epidemiology of adult fractures: a review. Injury. 2006;37(8):691-7.

24. Milzman DP, Boulanger BR, Rodriguez A, Soderstrom CA, Mitchell KA, Magnant CM. Pre-existing disease in trauma patients: a predictor of fate independent of age and injury severity score. J Trauma. 1992;32(2):236-43.

25. Hildebrand F, Pape HC, Horst K, Andruszkow H, Kobbe P, Simon $\mathrm{TP}$, et al. Impact of age on the clinical outcomes of major trauma. Eur J Trauma Emerg Surg. 2016;42(3):317-32.

26. Taghavi S, Jayarajan SN, Duran JM, Gaughan JP, Pathak A, Santora TA, et al. Does payer status matter in predicting penetrating trauma outcomes? Surgery. 2012;152(2):227-31.

27. White FA, French D, Zwemer FL, Fairbanks RJ. Care without coverage: is there a relationship between insurance and ED care. J Emerg Med 2007;32(2):159-65

28. Kruithof N, de Jongh MA, de Munter L, Lansink KW, Polinder $\mathrm{S}$. The effect of socio-economic status on non-fatal outcome after injury: a systematic review. Injury. 2017;48(3):578-90.

29. Popal Z, Berkeveld E, Ponsen KJ, Goei H, Bloemers FW, Zuidema WP, et al. The effect of socioeconomic status on severe traumatic injury: a statistical analysis. Eur J Trauma Emerg Surg. 2019;12:10-23.

30. Schneider MA, Rickenbacher A, Frick L, Cabalzar-Wondberg D, Kaser S, Clavien PA, et al. Insurance status does not affect short-term outcomes after oncological colorectal surgery in Europe, but influences the use of minimally invasive techniques: a propensity score-matched analysis. Langenbecks Arch Surg. 2018;403(7):863-72. 